$10-31-2020$

\title{
Frontline Health: Harmonizing metrics, advancing evidence, accelerating policy-Project overview brief
}

Frontline Health Project

Follow this and additional works at: https://knowledgecommons.popcouncil.org/departments_sbsr-rh

Part of the Health Services Research Commons, International Public Health Commons, and the Maternal and Child Health Commons

How does access to this work benefit you? Let us know!

\section{Recommended Citation}

Frontline Health Project. 2020. "Frontline Health: Harmonizing metrics, advancing evidence, accelerating policy-Project overview brief." Washington, DC: Population Council. 


\section{FRONTLINE HEALTH: HARMONIZING METRICS, ADVANCING EVIDENCE, ACCELERATING POLICY}

\section{THE ISSUE}

Despite decades of technological and medical progress globally, half the world's population still lacks access to essential health care due to insufficient numbers and types of health workers, especially in remote settings (1). There is growing recognition that well-supported community health workers (CHWs) are essential for effective delivery of primary health care (PHC). Despite broad consensus on the importance of $\mathrm{CHWs}$, few countries have successfully integrated them as part of $\mathrm{PHC}$ at scale, and many lack official statistics on the performance of $\mathrm{CHW}$ programs (2).

In response to these challenges, USAID, UNICEF, and the Bill \& Melinda Gates Foundation developed a Memorandum of Understanding (MOU) to collaborate on a set of investment priorities that advance frontline delivery of PHC and community engagement in health systems through the Integrating Community Health $(\mathrm{ICH})$ partnership. The $\mathrm{ICH}$ partnership's aim is to advance global learning around the integration of community-based service delivery models in seven countries: Democratic Republic of Congo, Liberia, Bangladesh, Mali, Kenya, Uganda, and Haiti. The $\mathrm{ICH}$ partnership focuses specifically on strengthening the role of community health approaches, including $\mathrm{CHW}$ programming, to reduce barriers to health coverage and support national implementation plans and policies.

\section{WHAT IS A COMMUNITY HEALTH} WORKER (CHW)?

CHWs-defined as frontline health workers with up to six months of initial training, who live in the communities in which they serve-are often the first and only link to essential health services for millions of people worldwide. CHWs extend access to health services, save lives, and generate strong returns on investment.

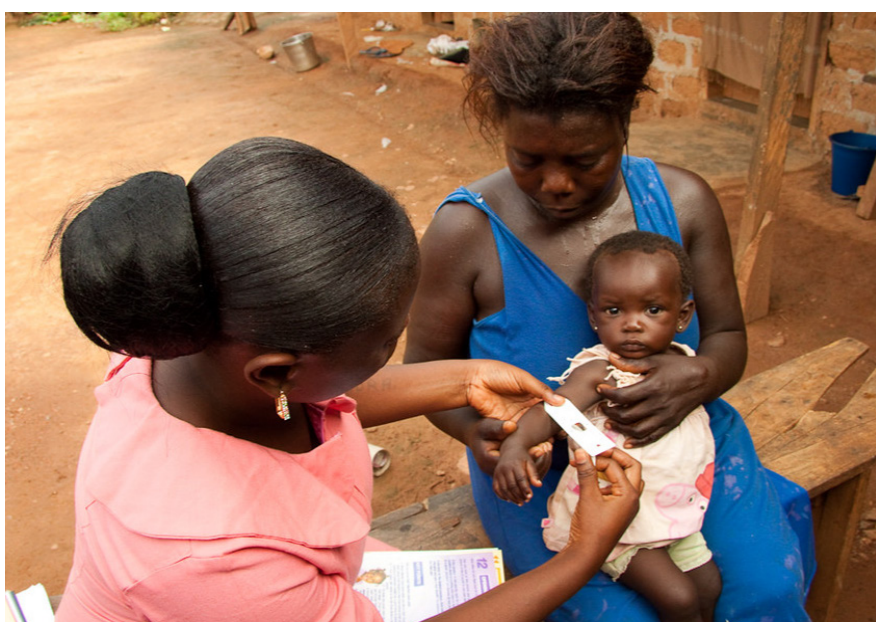

A CHW takes an infant's arm measurement in Uganda. Credit: Millennium Promise, 2014.

\section{WHAT IS THE FRONTLINE HEALTH PROJECT?}

Embedded within the $\mathrm{ICH}$ partnership, the Frontline Health project is a three-year joint research, policy, and advocacy endeavor of the Population Council and Last Mile Health which aims to:

- Lead the global measurement, learning, and evaluation around frontline delivery of $\mathrm{PHC}$ by developing a set of core measures for evaluating $\mathrm{CHW}$ performance and operationalize them in select countries.

- Build in-country capacity for routine metrics monitoring, research, and uptake to sustain community health systems.

- Accelerate the development and institutionalization of robust community health policies at national and subnational scales through reform and advocacy processes. 


\section{COMMUNITY HEALTH WORKER PERFORMANCE MEASUREMENT FRAMEWORK}

Coordinating performance metrics across diverse frontline health worker programs is essential to ensuring effective PHC models and advocating for scaled-up and improved programs. In 2018, the Population Council conducted an iterative literature review, drawing from existing $\mathrm{CHW}$ frameworks, metrics, and indicators lists, Monitoring, Evaluation \& Learning (MEL) plans from the seven $\mathrm{ICH}$ partner countries, and peer-reviewed and grey literature (3). This published literature review informed the development of the community health systems performance measurement framework (below).

We identified twenty-one sub-domains with 46 indicators for measurement, including measurement of incentives for $\mathrm{CHWs}$, supervision and performance appraisal, data use, data reporting, service delivery, quality of services, CHW absenteeism and attrition, community use of services, experience of services, referral/counter-referral, credibility/trust, and programmatic costs.

When prioritizing a shortlist from the 46 indicators for national monitoring and evaluation frameworks, countries should consider the maturity of the community health system; maturity can be observed in the degree to which the community health system is integrated with the formal health system at national, regional, district, and facility levels. Countries should also consider the types of data that are perceived as critical to advocate for such community-based interventions.

Some indicators in the framework will be more relevant to early $\mathrm{CHW}$ initiatives, while others will become useful as CHW service delivery becomes fully integrated into the health system. Other factors for $\mathrm{CHW}$ program and policy stakeholders to consider when using this framework include data usability, data collection capacity, feasibility for routine or special studies, and health information system capacity.

\section{FRONTLINE HEALTH RESEARCH AGENDA}

The evidence generated by the Frontline Health project will shape the global understanding of implementing performance metrics and promote frontline healthcare delivery programs and policies for replication across a variety of country settings.

Population Council's research agenda under the Frontline Health project explores the perspectives of $\mathrm{CHWs}$ and other stakeholders on a range of issues, including data use within countries, quality and experience of services provided by $\mathrm{CHWs}$ in various health areas, referral systems strengthening, application of digital tools in community health, and how community-based PHC-demonstrated resilience offers promising sustainability options in varied contexts.

The research also applies and develops performance measures to improve strategies for integrating locally

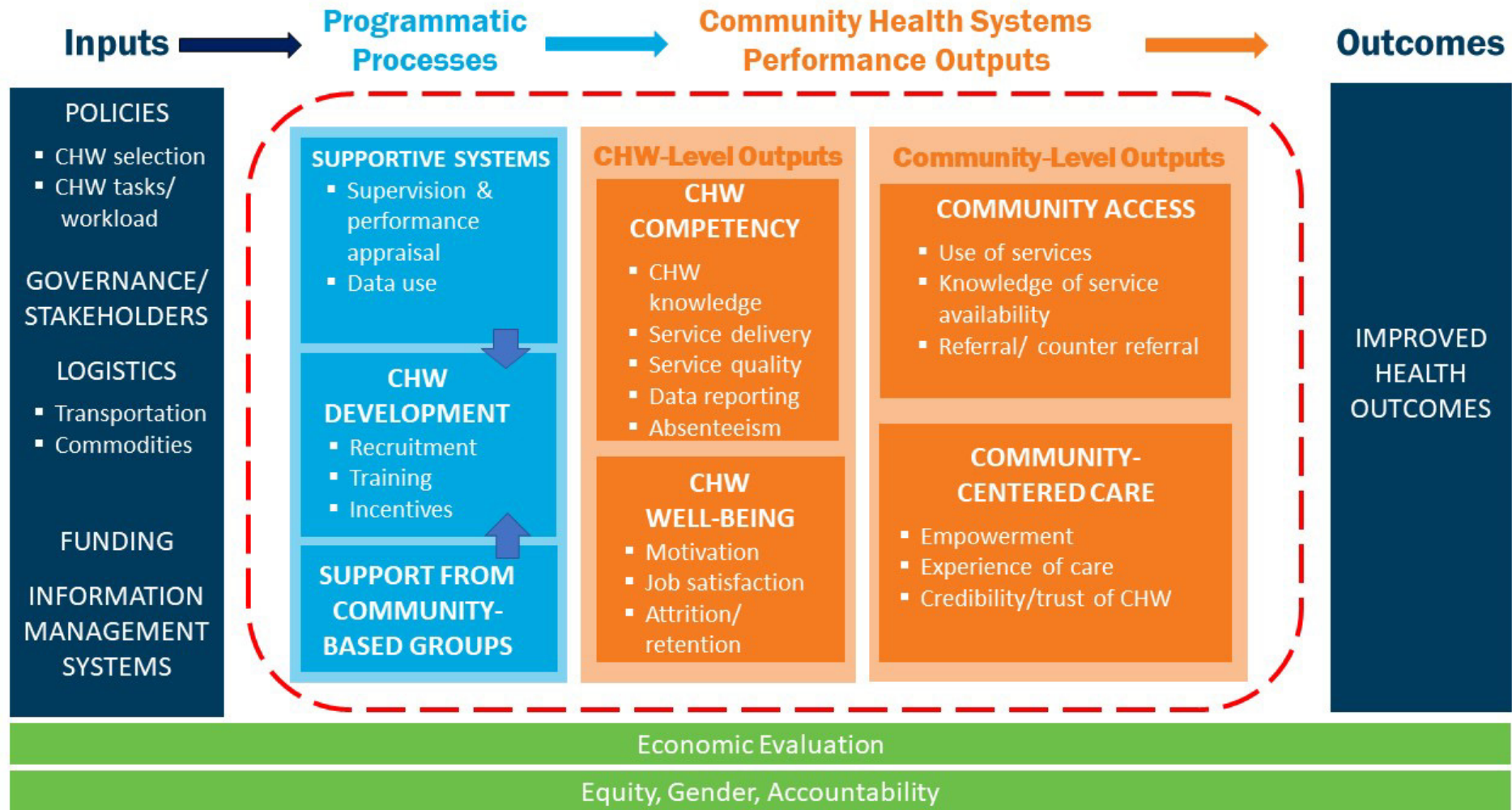


relevant metrics into national and global frameworks. Key measurement indicators in each country are shown on the map below.

\section{THE COMMUNITY HEALTH SYSTEMS REFORM CYCLE}

To develop guidance for governments and partners seeking to scale up $\mathrm{CHW}$ programs, Last Mile Health collected observations from the reform efforts of all seven $\mathrm{ICH}$ partner countries and reviewed literature in health system and policy reform, institutional development, and advocacy.

Based on their observations, they found that successful scale-up is a complex part of institutional reform that is driven by a strategic, problem-driven political process. In order to achieve successful scale-up, countries must draw their potential program models from available solutions in their health system contexts and align them with the existing resources, capabilities, and commitments of key health sector stakeholders. Additionally, successful scale-up emerges from iterative cycles of learning and improvement, rather than a single, linear effort.

Based on key findings, Last Mile Health identified eight stages of the reform process: Problem Prioritization, Coalition Building, Solution Gathering, Design, Program

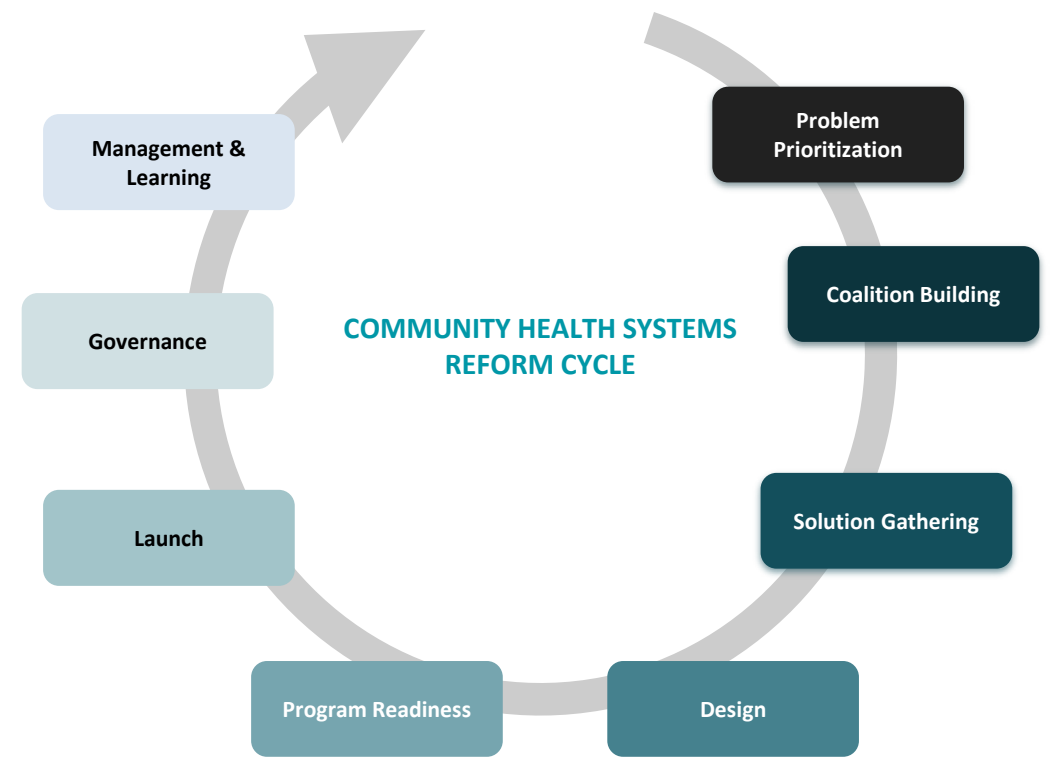

Readiness, Launch, Governance, and Management \& Learning.

Together, the stages offer a roadmap for governments, health sector partners, and other community health stakeholders seeking to support the scale-up of $\mathrm{CHW}$ programs. Potential reformers can use the cycle as a framework for assessing whether they have addressed the considerations critical to success, or can use it as planning tool to focus the reform efforts of health sector stakeholders.

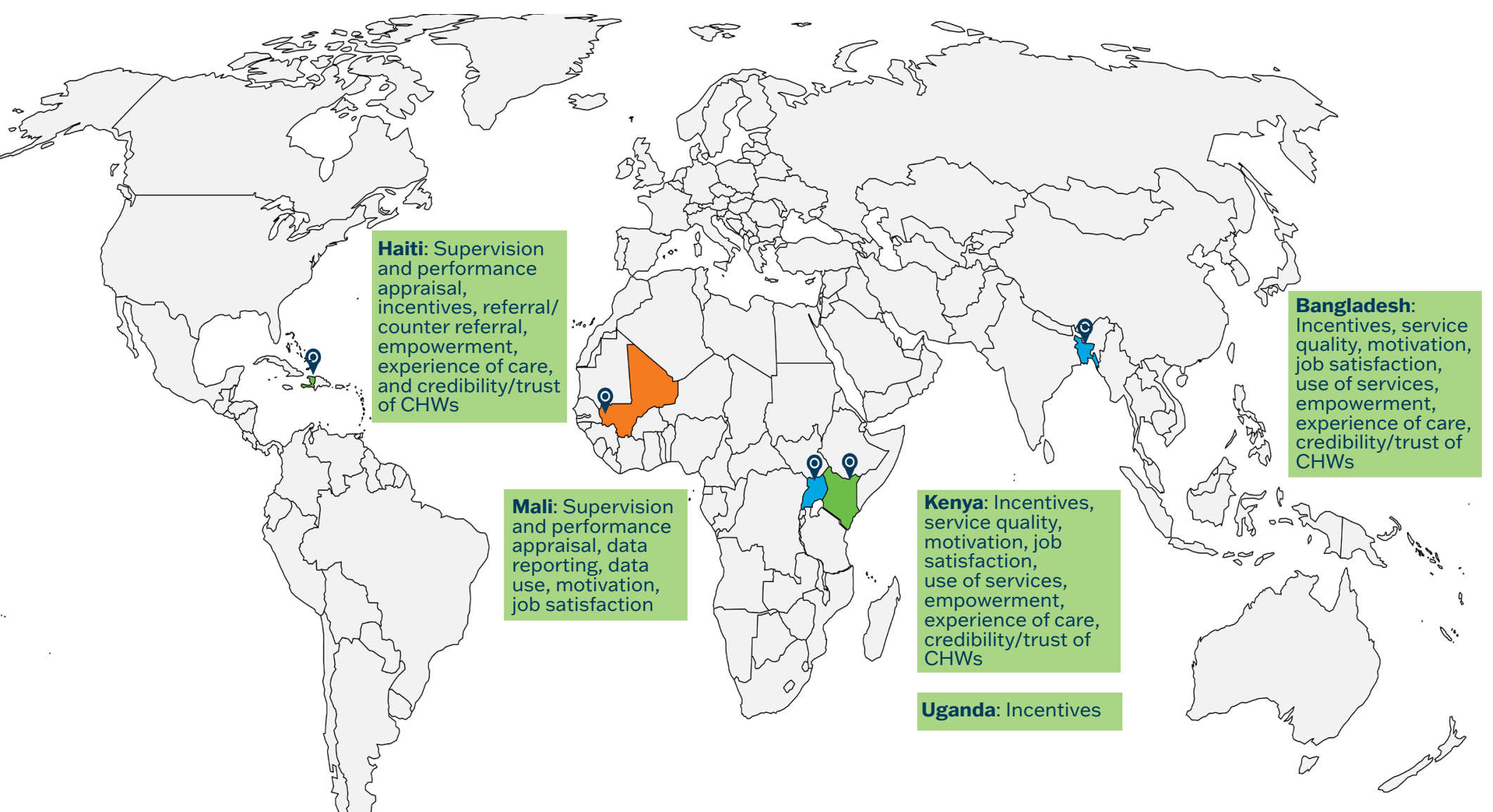




\section{FRONTLINE HEALTH PROGRESS AND NEXT STEPS}

Research findings from the Frontline Health project and ICH partnership will be available through multiple online forums, including two journal supplements in the Journal of Global Health and Global Health: Science and Practice. A practical guide on lessons learned from implementation and measure application and other knowledge products will also be available online by April 2021.

\section{CHWs in COVID Research}

In response to the threat COVID-19 poses for CHWs and the communities in which they live, Population Council has undertaken a separate research agenda under the Frontline Health Project, which will explore CHWs' experiences and perspectives of engaging with communities, providing routine and COVID19-specific care, and interacting with the broader health systems during the COVID-19 pandemic. This research is on-going in Bangladesh, Haiti, and Kenya. The project will use this research as it continues to provide evidence to support and guide national and subnational governments and Ministries of Health to sustain CHW programming.

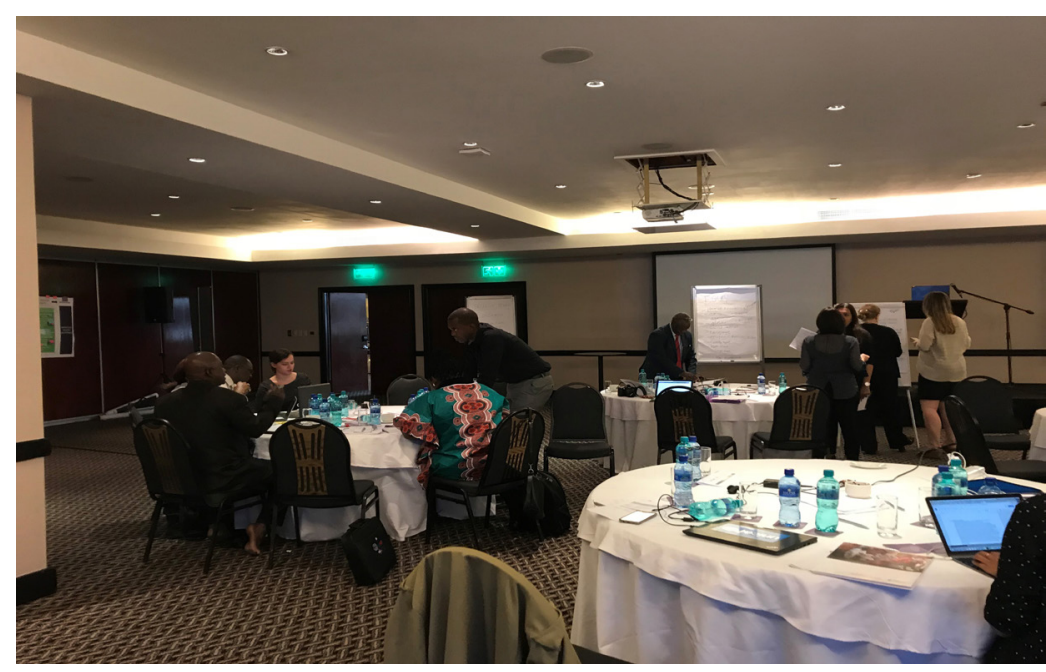

Population Council, Last Mile Health, and ICH policy and program stakeholders met at the ICH conference in Johannesburg in 2018, where the formative work for the project was done.

\section{REFERENCES}

1. World Health Organization and International Bank for Reconstruction and Development /World Bank. 2017. Tracking universal health coverage: 2017 global monitoring report. Available from: https://apps. who.int/iris/bitstream/handle/10665/259817/9789241513555-eng. pdf?sequence=1

2. Agarwal S, Sripad P, Johnson C, Kirk K, Bellows B, Ana J...CE Warren. (2019). A conceptual framework for measuring community health workforce performance within primary health care systems. Hum Resour Health, 17(1). doi:10.1186/s12960-019-0422-0

3. Agarwal S, Kirk K, Sripad P, Bellows B, Abuya T, CE Warren. (2019). Setting the global research agenda for community health systems: literature and consultative review. Hum Resour Health 17, 22. https:// doi.org/10.1186/s12960-019-0362-8

Suggested citation: Frontline Health Project. 2020. Frontline Health: Harmonizing Metrics, Advancing Evidence, Accelerating Policy Project Overview Brief. Washington, D.C.: Population Council.

\section{CONTACT}

Charlotte Warren, Senior Associate, Population Council, cwarren@popcouncil.org

Pooja Sripad, Associate, Population Council, psripad@popcouncil.org

Mallika Raghavan, Director of Country Engagement, Last Mile Health, mraghavan@lastmilehealth.org

The Frontline Health: Harmonizing Metrics, Advancing Evidence, Accelerating Policy project seeks to advance community health systems metrics, monitoring and learning to improve the efficiency and performance of community health worker programs. www.popcouncil.org/research/frontline-health-harmonizing-metrics-advancing-evidence 